threading our way through this verbiage we find a fascinating survey of earth's living things and the strange and often bizarre devices by which they survive and reproduce.

The subjects range in scale from Amoeba and diatoms to whales. There are interesting accounts of the almost incredible reproduction of bees, the development of vision in insects and vertebrates, electric animals, the elephant's trunk and the mating of this animal. A mere catalogue of the chapter headings would give the impression of a random selection of themes, and yet, skilfully, the author manages to demonstrate that underlying all these diverse topics there is a unity: of the amazing potential inherent in protoplasm. It is, perhaps, refreshing also to find a trained biologist who can feel wonder and even awe in the filigree cell-wall of a diatom or the splendid manoeuverability of a golden eagle in flight.

\title{
JOHN CLEGG
}

\section{The World of Birds. A Comprehensive Guide to Ornithology, by James Fisher and Roger Tory Peterson. Macdonald, $\notin 55$ s.}

Two well known and widely travelled ornithologists, British and American, the latter also a noted bird artist, have here combined their knowledge and skills to produce a spectacular book. The keynote is pictorial presentation of facts and principles, with a highly condensed text. A large format has been used (ca. $12 \frac{1}{2}^{\prime \prime} \times 9 \frac{1}{2}^{\prime \prime}$ ), and a heavy paper taking text and illustrations side by side ; in nearly two-thirds of the book there is colour on every page.

The first main section is a profusely illustrated summary of various aspects of avian biology, with emphasis on evolution and geography. The specific examples in the text and in the brilliant paintings are taken from a wide range of families and from all over the world; figures of 668 species are reproduced by eight-colour lithography. There follows a shorter blackand-white section on methods of observation, including photographic and sound recording. The other colour section consists of a series of maps, on a variety of projections, showing the range of every family (sometimes subfamily). Each map is headed by a few data on the group, such as known geological age, probable geographical origin, and number of included genera and species ; and also by a silhouette of a representative form (but lacking any indication of scale). One knows the limitations of such maps, necessarily based on information not everywhere complete and inevitably suggesting a more sharply defined and uniform distribution than commonly exists. But taken broadly as diagrams these are wonderfully effective, and as a collection unique. The final section discusses the relations between birds and man, ending with a passage on conservation. To this is appended a "red list" of species with populations at a dangerously low level, and a "black list" of those believed to have become extinct since A.D. 1600

\section{LANDSBOROUGH THOMSON}

\section{Cats of the World, by Armand Denis. Constable, 30s.}

It is curious that the cat family, many of whose members are admired by all who visit zoos or, better still, see them in the wild, should have so little of their natural history recorded. As far as it is possible to remedy this, for there are still many aspects of the lives of cats to be explored, Armand Denis has done so. The author can scarcely need any introduction-at least to viewers of television-and this long needed book will, I feel sure, add to his reputation. It is magnificently illustrated, factual, well documented, and readable-no mean quality in a book of this kind. Though the 